\title{
Why do patients with minor complaints choose emergency departments and does satisfaction with primary care services influence their decisions? - CORRIGENDUM
}

Yakup Akpinar, Hakan Demirci, Ersin Budak, Ayse Karalar Baran, Ali Candar and Gokhan Ocakoglu

doi: https://doi.org/10.1017/S1463423617000822, Published by Cambridge University Press, 18 December 2017.

Key words: continuity of care; emergency medicine/urgent care; family health; primary care; quality of care; referral system

First published online 24 January 2018

In the article by Akpinar et al (2017), the name of a hospital was mistakenly listed as "XXXXX" in the abstract. The authors and the publishers would like to apologies for this mistake. The abstract sentence should read:

"In this study, a self-completed survey called EUROPEP was given to 535 outpatients who were admitted to the Bursa Yuksek Ihtisas Training and Research Hospital in Bursa and examined in the green zone in July 2015."

\section{Reference}

Akpinar, Y., Demirci, H., Budak, E., Baran, A.K., Candar, A. and Ocakoglu, G. 2017: Why do patients with minor complaints choose emergency departments and does satisfaction with primary care services influence their decisions? Primary Health Care Research and Development, doi: 10.1017/ S1463423617000822, published online 18 December 2017. 